\title{
COVID-19, adrenal gland, glucocorticoids, and adrenal insufficiency
}

\author{
Emin Murat Akbas ${ }^{\mathrm{a}}$, Nergis Akbas ${ }^{\mathrm{b}}$
}

\begin{abstract}
The current Coronavirus disease outbreak requires that physicians work in collaboration with other physicians especially in intensive care and emergency units. To fight against this new disease, whose pathogenesis, effects, and results have not been clearly demonstrated, especially in patients with the pre-existing chronic disease, requires special expertise and perspectives. Due to the need for dynamic glucocorticoid treatment at different stages of the disease in patients with adrenal insufficiency, the existence of reports indicating that "coronavirus disease 2019" also affects the adrenal reserve, and the use of glucocorticoids also in advanced stages in patients with Coronavirus disease require this issue to be emphasized with precision. Herein, treatment of the pre-existing adrenal insufficiency in patients with actual Coronavirus disease and the effects of the this critical disease on the adrenal gland have been reviewed.
\end{abstract}

Key words: SARS-CoV-2, adrenal insufficiency, adrenal cortex, severe acute respiratory syndrome, glucocorticoids

Received: November 20, 2020; Revised: January 13, 2021; Accepted: January 21, 2021; Available online: February 4, 2021

https://doi.org/10.5507/bp.2021.011

(c) 2021 The Authors; https://creativecommons.org/licenses/by/4.0/

${ }^{a}$ Erzincan Binali Yıldırım University, School of Medicine, Mengucek Gazi Training and Research Hospital, Department of Endocrinology, Erzincan, Turkey

${ }^{b}$ Mengucek Gazi Training and Research Hospital, Department of Obesity, Biochemistry, Erzincan, Turkey

Corresponding author: Emin Murat Akbas, e-mail:dremakbas@hotmail.com

\section{INTRODUCTION}

In December 2019, many patients presented with pneumonia caused by an unknown pathogen that was linked to a local market in Wuhan, China. Afterward, different from both Middle East Respiratory Syndrome Coronavirus (MERS-CoV) and Severe Acute Respiratory Syndrome Coronavirus (SARS-CoV), a new coronavirus was identified by sequencing the genome of the virus ${ }^{1}$. By the International Committee on Taxonomy of Viruses, Coronavirus Study Group, this new virus is named "Severe Acute Respiratory Syndrome Coronavirus 2 (SARSCoV-2)". Subsequently, the disease caused by the virus was named "Coronavirus Disease 2019" (COVID-19) $\left(\right.$ ref. $\left.^{2}\right)$.

SARS-CoV and SARS-CoV-2 have clearly stated biological, epidemiological, and pathological similarities. Their genes exhibit nearly $80 \%$ of identical sequences. Also, the receptor-binding domain structures of these two viruses are very similar ${ }^{3}$. However, our knowledge about virulence, pathogenesis, and treatment of the COVID-19 is still limited and has posed a major challenge especially for endocrinological diseases that require special approaches. Treatment modifications in patients with preexisting endocrine diseases as a consequence of infection and related situations are required to avoid complications and hospitalizations. For example, in patients with adrenal insufficiency (AI), in the presence of physical or psychological stress, changes in glucocorticoid (GC) doses should be made according to the "sick day rules". Considering the risk of adrenal crisis, the hospitalization threshold should be kept low in patients with AI.
As a matter of course, several concerns exist about these therapeutic approaches in patients with pre-existing and newly diagnosed adrenal insufficiency. First of all, in AI patients, GC replacement protocols during COVID-19 are not clear. The consequences of increasing the steroid dose in the infected individual to a sufficient amount to prevent an adrenal crisis or the amount of the adequate increase in a patient with COVID-19 are yet unknown. Second, the possible effects of COVID-19 on the adrenal gland, adrenal reserve, and peripheral GC dynamics are not clearly known in patients with or without AI. And finally, controversy continues regarding the necessity, timing, and dosage of GC replacement in Covid-19 patients, in patients without AI.

\section{DISCUSSION}

\section{COVID-19}

SARS-CoV was responsible for the outbreak in 20022004. Similar to the SARS-CoV, the primary target of SARS-CoV-2 is the whole respiratory tract and the most common clinical signs are fatigue, dry cough, fever, and dyspnea in advanced cases ${ }^{4}$. While substantially patients are asymptomatic or have a mild disease, unfortunately, in $10-20 \%$ of patients the disease progresses to a more severe form and may require hospitalization, even respiratory support in the intensive care unit ${ }^{5}$. Typical laboratory findings are elevated levels of C-reactive protein (CRP), d-dimer, lactate dehydrogenase, aspartate aminotransferase, and lymphopenia ${ }^{4}$. In a study aimed to search prognostic value of inflammatory markers in patients with 
COVID-19, the levels of IL-6, CRP, and procalcitonin increased significantly in $67.9 \%, 65.0 \%$, and $5.7 \%$ of patients on admission, respectively ${ }^{6}$. In the study, serum levels of IL-6 and CRP were found to be associated with disease severity and prognosis in COVID-19 patients. Similarly, studies and case series have been reported indicating that presepsine can be used as a prognostic factor in this patient group ${ }^{7,8}$. Risk factors for a poor outcome include; underlying comorbidities (chronic respiratory disease, obesity, diabetes, hypertension, cardiovascular disease), male gender, and older age ${ }^{9}$.

Current clinical management strategies include; symptomatic treatment, rehabilitation of pulmonary functions, and the control of inflammation, of course, in addition to strategies to prevent further dissemination of the virus. Unfortunately, effective and safe treatment options, such as an antiviral drug, a biological response modifier, or a vaccine that has been in widespread use is not yet available.

Some authors propose a 3-stage classification system to establish a standardized nomenclature, facilitate therapeutic application, and evaluate the response and clinical outcomes ${ }^{10-12}$. These stages are roughly divided by clinical and laboratory features with no clear or objective borders and are often overlapping (Fig. 1).

Stage I begins with the time of inoculation and includes the early phase of the disease. Angiotensinconverting enzyme-2 (ACE2), is the functional receptor of SARS-CoV-2 that provides viral entry into human cells in this phase ${ }^{13}$. ACE2 receptors are profusely present in the respiratory system. SARS-CoV-2, during this stage, multiplies and spreads primarily in the respiratory system. The majority of the patients are asymptomatic or have mild and often non-specific flu-like symptoms, such as fever, malaise, and a dry cough, mainly due to the viral infection itself. Diagnosis of the disease at this stage includes the detection of viral components at respiratory samples with polymerase chain reaction, detection of viral IgG and IgM antibodies, and other supportive tests such as chest imaging, CRP, liver function tests, and complete blood count ${ }^{4}$. At this stage, treatment aims to provide symptomatic relief.

In the second stage, patients develop viral pneumonia and this stage is associated with pulmonary inflammation and coagulopathy. Usually, chest images present bilateral infiltrates and/or ground-glass opacities. Blood tests may reveal lymphopenia, increasing transaminases, and other inflammation markers. Increased levels of inflammatory biomarkers such as CRP, IL-6, IL-1, ferritin, and D-dimer are associated with the development of Acute Respiratory Distress Syndrome (ARDS) and a poor clinical course ${ }^{6-8,14,15}$. During this stage, viral pneumonia and inflammation cause cough, fever, and hypoxia in severe cases. The majority of the patients in this stage would need to be hospitalized for closer follow-up and necessary treatments or respiratory support. In this period, treatment generally also includes supportive treatment and available anti-viral medications.

A small number of patients will advance to the "extrapulmonary systemic hyper inflammation syndrome" stage, the third and the most severe stage of the illness. In this stage, infection results in a decrease in helper, suppressor, and regulatory $\mathrm{T}$ cell counts; and an increase in inflammatory cytokines and biomarkers ${ }^{10,14}$. Shock, vascular collapse, vasoplegia, systemic organ involvement, and even organ failures can be seen at this stage. As a result, the prognosis at the critical stage of the illness is poor, depends on rapid recognition, and therapies such as immunomodulatory and anti-inflammatory drugs. Tailored therapies in this stage would aim to reduce systemic inflammation and avoid multiorgan dysfunction.

\section{COVID-19 and Adrenal Gland}

Although data on cortisol release dynamics in COVID-19 patients are not yet available, based on data we have obtained from outbreaks caused by other members of this virus family, we may suggest that severe COVID-19 patients may be more prone to developing "Critical Illness Associated Corticosteroid Deficiency (CIRCI)" ( ref. $^{16}$ ).

It has been reported that the SARS-CoV, as in the influenza virus, inhibits the adrenal stress response of the host by various mechanisms, thus causing a relative adrenocortical insufficiency, provoking the symptoms and clinical manifestations of the disease it causes. One of these mechanisms is that the virus expresses certain amino acid sequences by mimicking the host's adrenocorticotropin hormone. Antibodies developed against these amino acid sequences also affect the function of the host's ACTH hormone. Along with the effects of ACTH, the adrenal stress response is also limited ${ }^{17}$. Considering the similarity of SARS-CoV-2 proteins to SARS proteins (95-

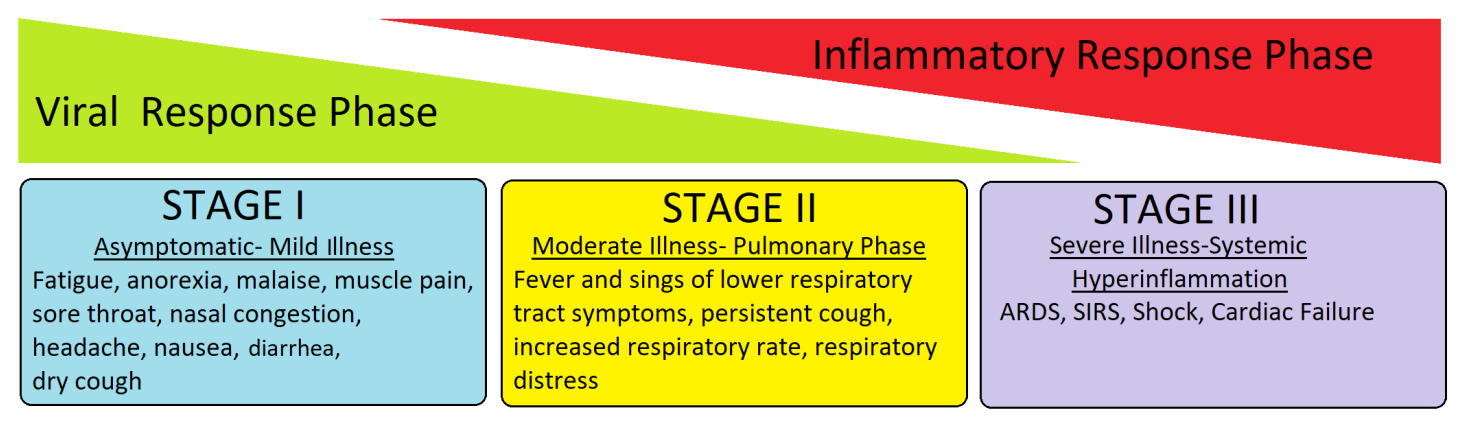

Fig. 1. Proposal for Stages of Covid-19, a 3-stage classification system to establish a standardized nomenclature, facilitate therapeutic application, and evaluate the response and clinical outcomes. 
$100 \%$ ), it can be thought that SARS-CoV-2 uses the same strategy ${ }^{18}$.

Data from the SARS outbreak suggests that this disease (possibly also COVID-19) can affect the hypothalamic-pituitary-adrenal (HPA) axis. Leow et al. find out $40 \%$ of survivors of the SARS outbreak had central hypocortisolism when evaluated 3 months after illness and periodically thereafter; which most of the cases resolved within a year. The authors suggested that this dysfunction may be due to reversible hypophysitis or direct hypothalamic injury ${ }^{19}$. Additionally, supporting this suggestion, autopsy studies revealed neuronal degeneration and edema along with the SARS-CoV genome in the hypothalamus ${ }^{20,21}$. Hypothalamic and pituitary tissues express ACE2, making these tissues targets for SARS-Cov- 2 (ref. ${ }^{20}$ ). Although we do not have sufficient data for now, considering the neurological symptoms, it can be thought that the hypothalamus and pituitary are affected directly or immunemediated in COVID-19.

Autopsy findings in patients who died from SARS demonstrated degeneration and necrosis of adrenal cortical cells, indicating a direct cytopathic effect of the virus $^{22,23}$. Moreover, viral antigens and the genomic sequence of SARS-CoV were demonstrated in the adrenal glands ${ }^{23}$. Therefore, in patients with SARS (and possibly also with COVID-19), cortisol dynamics are likely to be changed. Similarly, microscopic lesions in the adrenal glands were found in 46 percent (12 of 28) of patients in whom adrenal insufficiency was not detected in 28 autopsies with a confirmed SARS-CoV-2 infection ${ }^{24}$. Unspecific focal adrenalitis, necrosis, lipid degeneration, vascular thrombosis, hemorrhage, and focal inflammation are the microscopic findings observed in these cases ${ }^{24}$.

The coagulation disorders and its treatment with anticoagulants such as heparin in COVID-19 patients have been revealed by recent findings ${ }^{25,26}$. Therefore, considering the thromboembolic situation at the adrenal gland in COVID-19 patients, one can assume that SARS-CoV-2 infection, also in this way, may cause an acute adrenal insufficiency. On the other hand, also supporting the autopsy studies, the study reported by Leyendecker et al, revealed $23 \%$ of 219 patients with critical and severe lung parenchyma lesions had CT scan signs of acute adrenal infarction (which was bilateral in $88 \%$ and had an acute adrenal gland insufficiency in $8 \%$ ) ( ref. $^{27}$ ). Supporting these findings, case reports have been published reporting bilateral adrenal hemorrhage and/or AI (ref. ${ }^{28,29}$ ).

Additionally, as noted in other critical illnesses, residual adrenal functions in primary and central AI patients can be affected in patients with COVID-19 pneumonia ${ }^{16}$. Moreover, the long-term steroid treatment, the most common cause observed in the general population, should be kept in mind as another cause of AI insufficiency. Especially if given more than supra-physiological doses, and if administered in a non-circadian fashion and/or more than two to four weeks.

Finally, the effects of other medications used in the treatment of COVID-19 should be kept in mind. For example, it should be noted that ritonavir inhibits the cytochrome P4503A enzyme, thus increasing exposure to corticosteroids and prolonging their half-life ${ }^{30}$. It is noteworthy that following a cytokine storm there may be immune "exhaustion," and that even small variations in corticosteroid dynamics can be detrimental ${ }^{31}$. Over and above, even in Cushing Syndrome (CS), medications can cause adrenal insufficiency and might be a clinical challenge during COVID-19 infection ${ }^{32}$. According to the authors, physicians should consider the possibility of titrating or temporarily halting CS medical therapies in the sense of COVID-19 infection ${ }^{32}$.

Although it is not directly related to the effect of COVID-19 on adrenal gland function, another study that should be mentioned here is on the relationship between lymphopenia and cortisol. Panesar et al. had reported a significant inverse relationship between serum cortisol level and lymphocyte - neutrophil count in patients with SARS. Patients with lymphopenia had higher serum cortisol levels than those without lymphopenia, according to the study. According to the report, lymphopenia might be a sign of higher levels of serum cortisol ${ }^{33}$. While there is a lack of comparable evidence for COVID-19 as of now, the absence of lymphopenia in COVID-19 patients can be used as a reason to suspect low cortisol levels.

\section{Glucocorticoid Use In COVID-19 and Adrenal Suppression}

Despite many studies, the use of GC's in the treatment of coronavirus (such as SARS-CoV, SARS-CoV-2, and MERS-CoV) or influenza virus pneumonia is still controversial. It has been reported in different publications that GC's used in the treatment during the SARS epidemic have no benefit or have limited benefit, but may have adverse effects ${ }^{34-37}$. Although there is no evidence supported by randomized clinical studies for its use, in the current outbreak, GC's were empirically used to suppress cytokine storms and related complications, such as ARDS, acute heart injuries, and acute kidney complications ${ }^{38-40}$.

According to a systematic review, GC therapy did not reduce the ICU hospitalization period, admission rate, the mortality rate in patients affected by SARS-CoV-2, SARS-CoV, and MERS-CoV (ref. ${ }^{41}$ ). Similarly, another systematic review of observational studies reported no survival benefit and possible harms of GC such as avascular necrosis, psychosis, diabetes, and delayed viral clearance in patients in SARS-CoV ( ref. $^{42}$ ). Additionally, reports revealed the reduced clearance of SARS-CoV and MERS$\mathrm{CoV}$ from the plasma and/or the respiratory tract ${ }^{42-44}$. And also, these meta-analyses evaluate the studies with different doses and patient characteristics. Indeed, some trials have been done in patients with ARDS or septic shock, while others have enrolled patients with serious and/or traditional therapy-resistant conditions.

On the other hand, the use of dexamethasone resulted in lower 28-day mortality than in the normal treatment group in patients who required either invasive mechanical ventilation ( 29.3 percent vs. 41.4 percent) or oxygen alone (23.3 percent vs. 26.2 percent) at randomization but not among those receiving no respiratory support 
(17.8 percent vs. 14.0 percent) (ref. $\left.{ }^{45}\right)$. Similarly, early administration of dexamethasone could minimize the period of mechanical ventilation and overall mortality in patients with established ARDS in a study conducted at the ICU ( ref. $^{46}$ ).

Surviving sepsis guidelines suggest using GC's only for patients in whom hemodynamic control is not restored by sufficient fluids and vasopressor therapy ${ }^{47,48}$. In viral pneumonia, GC's should be used with caution, especially when there are specific conditions and comorbidities such as asthma exacerbation, chronic pulmonary obstructive disease, and septic shock refractory to fluid resuscitation $^{49}$. And in clinical practice, in a critical patient with COVID-19 and/or sepsis, physicians must reconcile the slight reduction in mortality rates with the potentially harmful results.

Glucocorticoid therapy may either cause CS at supraphysiologic doses or AI because of HPA axis suppression after drug withdrawal. In terms of increased morbidity and mortality risk, it may trigger outcomes in any direction. GC treatment is the most common cause of AI in the general population; especially if used for more than two to four weeks, it is administered in non-circadian and/ or supra-physiological doses. There is evidence of AI following low-dose and short-term GC use, that clinicians should be alert ${ }^{50}$. But especially, HPA suppression is likely in a patient who has used prednisone at a dose of $>20 \mathrm{mg}$ per day or an equivalent dose of GC (16 mg methylprednisolone, $80 \mathrm{mg}$ hydrocortisone, $2 \mathrm{mg}$ dexamethasone, 20 mg prednisolone) for more than three weeks; or a patient who has used $5 \mathrm{mg}$ prednisone or an equivalent dose of GC in the evening/bedtime for more than a few weeks; or in an individual using GC with the Cushingoid appearance, symptoms or signs ${ }^{51}$. HPA suppression is unlikely in a patient who has been treated with alternate-day prednisone at a dose of less than $10 \mathrm{mg}$ (or an equivalent dose), or a patient who has received any dose of glucocorticoid for less than three weeks ${ }^{51}$. There is an intermediate or unclear chance of HPA suppression in patients taking 10 to $20 \mathrm{mg}$ prednisone daily for more than three weeks, or in patients taking any dose less than $10 \mathrm{mg}$ prednisone daily for more than a couple of weeks that is not taken as a single bedtime dose ${ }^{51}$.

However, the suppression of the HPA axis by synthetic steroids, even after a short treatment period, cannot be predicted due to pathophysiological changes in cortisol dynamics in severe diseases, individual pharmacokinetic differences, and sensitivity variations in glucocorticoid receptors ${ }^{50}$. Moreover, the pathological adrenal changes in Covid-19 patients revealed in the previous section make the available information thoroughly complex and unreliable. Whenever the withdrawal of GC's is done, especially in patients at risk for HPA axis suppression, the dose should be carefully tapered and patients should be monitored for adrenal insufficiency. Evaluation of adrenal function should be performed at least one week after the withdrawal of GC (ref. ${ }^{52}$ ). When necessary, adrenal functions should be evaluated with dynamic tests.

\section{Adrenal Insufficiency In COVID-19}

AI patients, regardless of etiology, experience higher morbidity and mortality rates than the general population even when they receive optimal treatment. Impaired immunity functions, at least partially, may explain a slightly increased rate of infectious diseases in these patients and overall increased mortality ${ }^{53,54}$. There is no evidence, based on current data, that patients with adrenal insufficiency have an increased risk of COVID-19. However, in a study conducted in Italy, the prevalence of covid-19 in patients with adrenal insufficiency (prevalence $0.8 \%$ ) was found to be lower than the prevalence of the normal population, and these patients were considered as "not at particular risk of COVID-19" (ref. ${ }^{55}$ ). This surprising result can be explained by the fact that this patient group is educated and attentive, compared to the normal population, due to the additional risks present. Indeed, one of the most important factors for the successful treatment of AI patients is to conduct patient education and update it when necessary. All patients with AI should be educated to increase the GC replacement dose during stress conditions (physical or emotional stress), how and when to inject the intramuscular emergency GC kit, and in what situations to contact their physician. In addition to educational strategies, all patients with AI should be instructed to wear information accessories (bracelets-necklaces) that will attract the attention of healthcare professionals in case of loss of consciousness and should be instructed to have an identification card stating the AI diagnosis. Moreover, patients are also recommended to have sufficient stock at the home of steroid pills and injections, considering social isolation and quarantine requirements in most of the countries for impeding the COVID-19 outbreak spread.

In AI patients, it is important to determine the quantity and timing of GC administration (stress dose) depending on the degree of stress, not too early or not too late. We believe that, in patients with Covid-19, staging the disease is essential in determining this timing and clarifying the dose increase, as stated in the previous section.

If patients are asymptomatic in Stage I, intervention in their routine treatment should be avoided. If there is, mineralocorticoid treatment should be continued. When patients present only mild symptoms and signs (such as mild intermittent cough, fever $<38{ }^{\circ} \mathrm{C}$, sore throat, diarrhea, nasal congestion), and no symptoms of respiratory impairment at the early stage of symptomatic disease, doubling the usual dose is sufficient to replace the missing increase in stress-induced cortisol. It is recommended to preserve the circadian rhythm as much as possible at this stage. Some recommendations, however, state that infection with Covid-19 requires the need for the more uniform night and day coverage of GC's because it is associated with severe inflammation and persistent high fever ${ }^{56}$. Therefore, in case of further progression of symptoms in stage I (fever> $38^{\circ} \mathrm{C}$ or continuous dry cough, sore throat, aches and pains, fatigue), considering the emotional or physical stress, increasing the dose to $20 \mathrm{mg}$ hydrocortisone orally every 6 hours may be more appropriate (in 
Table 1. Treatment suggestions and recommendations according to the stage of the disease.

\begin{tabular}{|c|c|c|c|}
\hline Stage & Situation & Dose Suggestions & Recommendations \\
\hline \multirow[t]{3}{*}{ Stage 1} & Asymptomatic & Routine Treatment. & $\begin{array}{l}\text { Monitor closely for symptoms and signs. } \\
\text { Evaluate and update patient education. }\end{array}$ \\
\hline & Mild Illness & Double / thrice the usual dose. & $\begin{array}{l}\text { Monitor closely for pulmonary functions, patient } \\
\text { distress, symptoms and signs of the next stage. }\end{array}$ \\
\hline & $\begin{array}{l}\text { Mild illness with mild } \\
\text { to modarete physical } \\
\text { or psychogenic stress, } \\
\text { further progression of } \\
\text { symptoms in stage I. }\end{array}$ & $\begin{array}{l}20 \mathrm{mg} \text { hydrocortisone QID } \\
\text { (10 mg prednisolone BID) }\end{array}$ & $\begin{array}{l}\text { Monitor closely for pulmonary functions, patient } \\
\text { distress, symptoms and signs of the next stage. } \\
\text { Keep the hospitalization threshold low. } \\
\text { Discontinue mineralocorticoid therapy if present } \\
\text { in case of using hydrocortisone }>50 \mathrm{mg} \text {. } \\
\text { Consider parenteral treatment in case of nausea or } \\
\text { vomiting. }\end{array}$ \\
\hline \multirow[t]{2}{*}{ Stage 2} & $\begin{array}{l}\text { Moderate Illness, } \\
\text { Pulmonary Phase }\end{array}$ & $\begin{array}{l}100 \mathrm{mg} / \text { day (parenteral preferenti- } \\
\text { ally) hydrocortisone. }\end{array}$ & $\begin{array}{l}\text { Consider parenteral therapy taking into account } \\
\text { symptoms and signs. } \\
\text { Consider hospitalization and continuous paren- } \\
\text { teral glucocorticoid infusion. } \\
\text { Monitor closely for fluid and electrolyte distur- } \\
\text { bances. }\end{array}$ \\
\hline & $\begin{array}{l}\text { Moderate Illness with } \\
\text { further progression of } \\
\text { symptoms and signs. }\end{array}$ & $\begin{array}{l}\text { Administer } 100 \mathrm{mg} \text { parenteral hydro- } \\
\text { cortisone immediately. } \\
\text { Until the patient begins to be moni- } \\
\text { tored in the inpatient unit administer } \\
50 \mathrm{mg} \text { hydrocortisone QID. } \\
50-100 \mathrm{mg} \text { hydrocortisone iv bolus } \\
\text { followed by } 200 \mathrm{mg} / \text { day iv infusion } \\
\text { in the inpatient unit. }\end{array}$ & $\begin{array}{l}\text { Monitor closely for fluid and electrolyte distur- } \\
\text { bances. } \\
\text { Monitor closely for inflammatory response phase, } \\
\text { pulmonary functions, patient distress, symptoms } \\
\text { and signs of the next stage. }\end{array}$ \\
\hline Stage 3 & $\begin{array}{l}\text { The deterioration of } \\
\text { the patient's clinical } \\
\text { condition or observa- } \\
\text { tion of the course of } \\
\text { ARDS. }\end{array}$ & $\begin{array}{l}200 \mathrm{mg} / \text { day iv hydrocortisone } \\
\text { infusion. }\end{array}$ & $\begin{array}{l}\text { Follow-up in the intensive care unit. } \\
\text { Monitor closely for fluid and electrolyte distur- } \\
\text { bances. }\end{array}$ \\
\hline $\begin{array}{l}\text { The } \\
\text { Recovery } \\
\text { Phase }\end{array}$ & Recovery & $\begin{array}{l}\text { Considering symptoms and signs, } \\
\text { the stress dose should be gradually } \\
\text { tapered to double the usual replace- } \\
\text { ment dose. } \\
\text { With a interim evaluation reduce to } \\
\text { the routine daily dose. }\end{array}$ & $\begin{array}{l}\text { Monitor closely for pulmonary functions, patient } \\
\text { distress, psychogenic stress, symptoms and signs. } \\
\text { Restart the discontinued mineralocorticoid } \\
\text { therapy if the hydrocortisone dose is }<50 \mathrm{mg} \text {. }\end{array}$ \\
\hline
\end{tabular}

patients using prednisolone; $10 \mathrm{mg} /$ twice a day) until the symptoms resolve. Treatment suggestions and recommendations according to the stage of the disease are shown in Table 1.

Unfortunately, a substantial number of patients (about $20 \%$ ) progress to the second stage. At this stage, the glucocorticoid dose of patients should be increased to at least $100 \mathrm{mg} /$ day hydrocortisone ${ }^{12}$. In particular, due to the lack of data on AI in covid-19, patients' emotional and physical stresses, and in this context, vital parameters (blood pressure, fever, heart and respiratory rate, respiratory functions, and peripheral oxygen saturation) should be closely monitored. Impairment in these parameters, or signs of emotional and/or physical stress, or the presence of symptoms such as nausea, vomiting, and diarrhea that prevent the patient's oral intake will constitute significant signs for the transition to parenteral therapy. If the patient's symptoms and signs are exacerbated, it would be appropriate to hospitalize the patient during this period and to administer $100 \mathrm{mg} /$ day parenteral hydrocortisone immediately ${ }^{56}$. Until the patient begins to be monitored in the inpatient unit, $50 \mathrm{mg}$ hydrocortisone should be administered every 6 hours ${ }^{56}$. In patients with adrenal insufficiency, the hospitalization threshold should be kept low, considering the risk of adrenal crisis. It is recommended to discontinue mineralocorticoid treatment at doses of $50 \mathrm{mg} /$ day and above.

The deterioration of the patient's clinical condition or observation of the course of ARDS will require higher GC doses. In this respect, 50-100 mg hydrocortisone iv bolus followed by $200 \mathrm{mg} /$ day iv infusion is recommend$\mathrm{ed}^{57}$. This protocol not only covers the amount of steroids 
required to deal with the infection but also reduces the detrimental effects caused by concentration peaks and troughs of GC on the immune system ${ }^{57}$.

Also, due to increased insensible fluid loss or altered consciousness, especially associated with fever and tachypnea, these patients may also have serious fluid and electrolyte disturbances. Close monitoring and reasonable replacement of water and electrolytes may be needed to prevent it. Additionally, thromboembolic predisposition observed in severe COVID-19 patients is a concern. Considering that the use of GC likewise predisposes to clotting abnormalities, it would be appropriate to plan low molecular weight heparin therapy as early as possible in this patient group.

It is recommended that at the time of discharge, the stress dose of GC should be gradually tapered to double the usual replacement dose and thereafter reducing it to the routine replacement dose. Similarly, when the daily hydrocortisone dose is reduced to $<50 \mathrm{mg}$ /day, the routine fludrocortisone dose should be added to the treatment.

\section{CONCLUSIONS}

In an individual without known adrenal insufficiency, covid-19 can change adrenal reserve, adrenal hormone release, and peripheral hormone dynamics. Moreover, discussions about when and how to perform GC replacement and whether it is necessary, in covid-19 patients without adrenal insufficiency are still ongoing. In this context, patients with adrenal insufficiency and covid-19 require closer attention and follow-up. Symptoms and signs of patients with Covid-19 should be closely monitored; their physical or emotional stresses should be taken into account, and tailored, dynamic glucocorticoid replacement therapy should be applied with a lower hospitalization threshold.

\section{Search strategy and selection criteria}

Optimal management of adrenal insufficiency amid the ongoing pandemic, effects of Covid-19 on the adrenal gland, necessity of the use of GC, and consequent adrenal gland suppression are discussed in this review. In these contexts, a literature search was performed to answer clinical questions. Scientific articles from January 2020 to November 2020 were searched using the PubMed and Web of Science databases. All searches were up to date as of November 2020. For the literature search, the term "adrenal insufficiency" and one of the following used respectively; "COVID-19", "Coronavirus", "Severe Acute Respiratory Syndrome", "SARS-CoV-2" and "coronavirus disease 2019". And references of selected articles were searched manually for additional relevant articles. Only English language papers were reviewed.

Author contributions: EMA: manuscript writing, literature search, figures; NA: literature search, manuscript writing, figures.
Conflict of interest statement: The authors state that there are no conflicts of interest regarding the publication of this article.

\section{REFERENCES}

1. Zhu N, Zhang D, Wang W, Li X, Yang B, Song J, Zhao X, Huang B, Shi W, Lu R, Niu P, Zhan F, Ma X, Wang D, Xu W, Wu G, Gao GF, Tan W. A Novel Coronavirus from Patients with Pneumonia in China, 2019. NEJM 2020;382(8):727-33.

2. Coronaviridae Study Group of the International Committee on Taxonomy of Viruses. The species Severe acute respiratory syndrome-related coronavirus: classifying 2019-nCoV and naming it SARS-CoV-2. Nat Microbiol. 2020 Apr;5(4):536-544. doi: 10.1038/ s41564-020-0695-Z

3. Lu R, Zhao X, Li J, Niu P, Yang B, Wu H, Wang W, Song H, Huang B, Zhu N. Genomic characterisation and epidemiology of 2019 novel coronavirus: implications for virus origins and receptor binding. Lancet 2020;395(10224):565-74.

4. Lake MA. What we know so far: COVID-19 current clinical knowledge and research. Clin Med (Lond) 2020;20(2):124-27.

5. Phua J, Weng L, Ling L, Egi M, Lim CM, Divatia JV, Shrestha BR, Arabi YM, Ng J, Gomersall CD. Intensive care management of coronavirus disease 2019 (COVID-19): challenges and recommendations. Lancet Respir Med 2020;8(5):506-17.

6. Liu F, Li L, Xu M, Wu J, Luo D, Zhu Y, Li B, Song X, Zhou X. Prognostic value of interleukin-6, C-reactive protein, and procalcitonin in patients with COVID-19. J Clin Virol 2020:104370.

7. Zaninotto M, Mion MM, Cosma C, Rinaldi D, Plebani M. Presepsin in risk stratification of SARS-CoV-2 patients. Clin Chim Acta 2020;507:161-63.

8. Fukada A, Kitagawa Y, Matsuoka M, Sakai J, Imai K, Norihito T, Orihara Y, Kawamura R, Takeuchi S, Maesaki S. Presepsin as a predictive biomarker of severity in COVID-19: a case series. J Med Virol 2020;Jun 12:10.1002/jmv.26164. doi: 10.1002/jmv.26164 [Epub ahead of print]

9. Zhou F, Yu T, Du R, Fan G, Liu Y, Liu Z, Xiang J, Wang Y, Song B, Gu $X$. Clinical course and risk factors for mortality of adult inpatients with COVID-19 in Wuhan, China: a retrospective cohort study. Lancet 2020;395(10229):1054-62.

10. Siddiqi HK, Mehra MR. COVID-19 illness in native and immunosuppressed states: A clinical-therapeutic staging proposal. J Heart Lung Transplant 2020;39(5):405-7.

11. Polak SB, Van Gool IC, Cohen D, Jan H, van Paassen J. A systematic review of pathological findings in COVID-19: a pathophysiological timeline and possible mechanisms of disease progression. Mod Pathol 2020;33(11):2128-38. doi: 10.1038/s41379-020-0603-3

12. Isidori A, Arnaldi G, Boscaro M, Falorni A, Giordano C, Giordano R, Pivonello R, Pofi R, Hasenmajer V, Venneri M. COVID-19 infection and glucocorticoids: update from the Italian Society of Endocrinology Expert Opinion on steroid replacement in adrenal insufficiency. J Endocrinol Invest 2020:43(8):1141-47.

13. Hamming I, Timens W, Bulthuis M, Lely A, Navis Gv, van Goor H. Tissue distribution of ACE2 protein, the functional receptor for SARS coronavirus. A first step in understanding SARS pathogenesis. J Pathol 2004;203(2):631-37.

14. Wu C, Chen X, Cai Y, Zhou X, Xu S, Huang H, Zhang L, Zhou X, Du $C$, Zhang $Y$. Risk factors associated with acute respiratory distress syndrome and death in patients with coronavirus disease 2019 pneumonia in Wuhan, China. JAMA Intern Med. JAMA Intern Med 2020;180(7):934-43

15. Zhou F, Yu T, Du R, Fan G, Liu Y, Liu Z, Xiang J, Wang $Y$, Song B, Gu X, Guan L, Wei Y, Li H, Wu X, Xu J, Tu S, Zhang Y, Chen H, Cao B. Clinical course and risk factors for mortality of adult inpatients with COVID-19 in Wuhan, China: a retrospective cohort study. Lancet 2020;395(10229):1054-62. doi: 10.1016/S0140-6736(20)30566-3 Erratum in: Lancet 2020;395(10229):1038

16. Téblick A, Peeters B, Langouche L, Van den Berghe G. Adrenal function and dysfunction in critically ill patients. Nat Rev Endocrinol 2019;15(7):417-27.

17. Wheatland R. Molecular mimicry of ACTH in SARS-implications for corticosteroid treatment and prophylaxis. Med Hypotheses 2004;63(5):855-62. 
18. Xu J, Zhao S, Teng T, Abdalla AE, Zhu W, Xie L, Wang Y, Guo X. Systematic comparison of two animal-to-human transmitted human coronaviruses: SARS-CoV-2 and SARS-CoV. Viruses 2020;12(2):244.

19. Leow MKS, Kwek DSK, Ng AWK, Ong KC, Kaw GJL, Lee LSU. Hypocortisolism in survivors of severe acute respiratory syndrome (SARS). Clin Endocrinol (Oxf) 2005;63(2):197-202.

20. Pal R, Banerjee M. COVID-19 and the endocrine system: exploring the unexplored. J Endocrinol Invest 2020;43(7):1027-31.

21. Pal R. COVID-19, hypothalamo-pituitary-adrenal axis and clinical implications. Endocrine 2020;68(2):251-52.

22. Ding Y, Wang H, Shen H, Li Z, Geng J, Han H, Cai J, Li X, Kang W, Weng $\mathrm{D}$. The clinical pathology of severe acute respiratory syndrome (SARS): a report from China. J Pathol 2003;200(3):282-89.

23. Gu J, Korteweg C. Pathology and pathogenesis of severe acute respiratory syndrome. Am J Pathol 2007;170(4):1136-47.

24. Santana MF, Borba MGS, Baía-da-Silva DC, Val F, Alexandre MAA, Brito-Sousa JD, Melo GC, Queiroga MVO, Farias MEL, Camilo CC. Case Report: Adrenal Pathology Findings in Severe COVID-19: An Autopsy Study. Am J Trop Med Hyg 2020;103(4):1604-7.

25. Porfidia A, Pola R. Venous thromboembolism in COVID-19 patients. J Thromb Haemost 2020;18(6):1516-17.

26. Mihaila RG, Mihaila MD. Coagulation disorders in SARS-CoV-2 infection. Biomed Pap Med Fac Univ Palacky Olomouc Czech Repub 2020;164(3):226-35.

27. Leyendecker P, Ritter S, Riou M, Wackenthaler A, Meziani F, Roy C, Ohana M. Acute adrenal infarction as an incidental CT finding and a potential prognosis factor in severe SARS-CoV-2 infection: a retrospective cohort analysis on 219 patients. Eur Radiol 2020;27:1-6.

28. Frankel M, Feldman I, Levine M, Frank Y, Bogot NR, Benjaminov $\mathrm{O}$, Kurd R, Breuer GS, Munter G. Bilateral adrenal hemorrhage in Coronavirus disease 2019 patient: A case report. J Clin Endocrino Metab 2020;105(12):dgaa487.

29. Heidarpour M, Vakhshoori M, Abbasi S, Shafie D, Rezaei N. Adrenal insufficiency in coronavirus disease 2019: a case report. J Med Case Rep 2020;14(1):1-4.

30. Epperla N, McKiernan F. latrogenic Cushing syndrome and adrenal insufficiency during concomitant therapy with ritonavir and fluticasone. Springerplus 2015;4(1):455.

31. Hirano T, Murakami M. COVID-19: A new virus, but a familiar receptor and cytokine release syndrome. Immunity 2020;19;52(5):731-33.

32. Beretta F, Dassie F, Parolin M, Boscari F, Barbot M, Busetto L, Mion R, De Carlo E, Scaroni C, Fallo F. Practical Considerations for the Management of Cushing's Disease and COVID-19: A Case Report. Front Endocrinol (Lausanne) 2020;11:554.

33. Panesar N, Lam C, Chan M, Wong C, Sung J. Lymphopenia and neutrophilia in SARS are related to the prevailing serum cortisol. Eur J Clin Invest 2004;34(5):382-84.

34. Auyeung TW, Lee JS, Lai WK, Choi CH, Lee HK, Lee JS, Li PC, Lok KH, $\mathrm{Ng}$ YY, Wong WM. The use of corticosteroid as treatment in SARS was associated with adverse outcomes: a retrospective cohort study. J Infect 2005;51(2):98-102.

35. Ho JC, Ooi GC, Mok TY, Chan JW, Hung I, Lam B, Wong PC, Li PC, Ho $\mathrm{PL}$, Lam WK. High-dose pulse versus nonpulse corticosteroid regimens in severe acute respiratory syndrome. Am J Respir Crit Care Med 2003;168(12):1449-56.

36. Yam LY-C, Lau AC-W, Lai FY-L, Shung E, Chan J, Wong V, Group HKHASC. Corticosteroid treatment of severe acute respiratory syndrome in Hong Kong. J Infect 2007;54(1):28-39.

37. Chen R-c, Tang X-p, Tan S-y, Liang B-I, Wan Z-y, Fang J-q, Zhong N. Treatment of severe acute respiratory syndrome with glucosteroids: the Guangzhou experience. Chest 2006;129(6):1441-52.

38. Sun P, Lu X, Xu C, Sun W, Pan B. Understanding of COVID-19 based on current evidence. J Med Virol 2020;92(6):548-51.

39. Chan KW, Wong VT, Tang SCW. COVID-19: An update on the epidemiological, clinical, preventive and therapeutic evidence and guidelines of integrative Chinese-Western medicine for the management of 2019 novel coronavirus disease. Am J Chin Med 2020;48(03):73762.

40. Huang C, Wang Y, Li X, Ren L, Zhao J, Hu Y, Zhang L, Fan G, Xu J, Gu $X$. Clinical features of patients infected with 2019 novel coronavirus in Wuhan, China. Lancet 2020;395(10223):497-506.

41. Li H, Chen C, Hu F, Wang J, Zhao Q, Gale RP, Liang Y. Impact of corticosteroid therapy on outcomes of persons with SARS-CoV-2, SARS
CoV, or MERS-CoV infection: a systematic review and meta-analysis. Leukemia 2020;34(6):1503-11.

42. Stockman LJ, Bellamy R, Garner P. SARS: systematic review of treatment effects. PLoS Med 2006;3(9):e343.

43. Lee N, Chan KA, Hui DS, Ng EK, Wu A, Chiu RW, Wong VW, Chan PK, Wong K, Wong E. Effects of early corticosteroid treatment on plasma SARS-associated Coronavirus RNA concentrations in adult patients. J Clin Virol 2004;31(4):304-9.

44. World Health Organization. Clinical management of COVID-19: interim guidance, 27 May 2020. World Health Organization, 2020.

45. RECOVERY Collaborative Group, Horby P, Lim WS, Emberson JR, Mafham M, Bell JL, Linsell L, Staplin N, Brightling C, Ustianowski A, Elmahi E, Prudon B, Green C, Felton T, Chadwick D, Rege K, Fegan C, Chappell LC, Faust SN, Jaki T, Jeffery K, Montgomery A, Rowan K, Juszczak E, Baillie JK, Haynes R, Landray MJ. Dexamethasone in Hospitalized Patients with Covid-19 - Preliminary Report. N Engl J Med 2020 Jul 17:NEJMoa2021436. doi: 10.1056/NEJMoa2021436 Epub ahead of print

46. Villar J, Ferrando C, Martínez D, Ambrós A, Muñoz T, Soler JA, Aguilar G, Alba F, González-Higueras E, Conesa LA. Dexamethasone treatment for the acute respiratory distress syndrome: a multicentre, randomised controlled trial. Lancet Respir Med 2020;8(3):267-76.

47. Rhodes A, Evans LE, Alhazzani W, Levy MM, Antonelli M, Ferrer R, Kumar A, Sevransky JE, Sprung CL, Nunnally ME. Surviving sepsis campaign: international guidelines for management of sepsis and septic shock: 2016. Intensive Care Med 2017;43(3):304-77.

48. Alhazzani W, Møller MH, Arabi YM, Loeb M, Gong MN, Fan E, Oczkowski S, Levy MM, Derde L, Dzierba A. Surviving Sepsis Campaign: guidelines on the management of critically ill adults with Coronavirus Disease 2019 (COVID-19). Intensive Care Med 2020;46(5):854-87.

49. Koblizek V, Chlumsky J, Zindr V, Neumannova K, Zatloukal J, Zak J, Sedlak V, Kocianova J, Zatloukal J, Hejduk K. Chronic Obstructive Pulmonary Disease: official diagnosis and treatment guidelines of the Czech Pneumological and Phthisiological Society; a novel phenotypic approach to COPD with patient-oriented care. Biomed Pap Med Fac Univ Palacky Olomouc Czech Repub 2013;157(2):189-201.

50. Joseph RM, Hunter AL, Ray DW, Dixon WG, editors. Systemic glucocorticoid therapy and adrenal insufficiency in adults: a systematic review. Semin Arthritis Rheum 2016;46(1):133-41.

51. Glucocorticoid withdrawal [Internet]. Wolters Kluwer Health. 2020 [cited 1th November]. Available from: https://www.uptodate.com/ contents/glucocorticoid-withdrawal.

52. Isidori A, Arnaldi G, Boscaro M, Falorni A, Giordano C, Giordano R, Pivonello R, Pozza C, Sbardella E, Simeoli C. Towards the tailoring of glucocorticoid replacement in adrenal insufficiency: the Italian Society of Endocrinology Expert Opinion. J Endocrinol Invest 2020;43(5):683-96.

53. Bancos I, Hazeldine J, Chortis V, Hampson P, Taylor AE, Lord JM, Arlt W. Primary adrenal insufficiency is associated with impaired natural killer cell function: a potential link to increased mortality. Eur J Endocrinol 2017;176(4):471-80

54. Isidori AM, Venneri MA, Graziadio C, Simeoli C, Fiore D, Hasenmajer V, Sbardella E, Gianfrilli D, Pozza C, Pasqualetti P. Effect of once-daily, modified-release hydrocortisone versus standard glucocorticoid therapy on metabolism and innate immunity in patients with adrenal insufficiency (DREAM): a single-blind, randomised controlled trial. Lancet Diabetes Endocrinol 2018;6(3):173-85.

55. Martino M, Aboud N, Cola MF, Giancola G, Ciarloni A, Salvio G, Arnaldi G. Impact of COVID-19 pandemic on psychophysical stress in patients with adrenal insufficiency: the CORTI-COVID study. J Endocrinol Invest 2020;Sep 18;1-10. doi: 10.1007/s40618-020-014222 Online ahead of print.

56. Arlt W, Baldeweg SE, Pearce SH, Simpson HL. Endocrinology in the time of COVID-19: Management of adrenal insufficiency. Eur J Endocrinol 2020;183(1):G25-G32.

57. Prete A, Taylor AE, Bancos I, Smith DJ, Foster MA, Kohler S, FazalSanderson V, Komninos J, O'Neil DM, Vassiliadi DA. Prevention of adrenal crisis: cortisol responses to major stress compared to stress dose hydrocortisone delivery. J Clin Endocrinol Metab 2020;105(7):2262-74. 